\title{
La importancia de cuidar
}

Editorial

Pedro tiene 84 años, es viudo desde hace 4 años y solo tiene un hijo que, en la medida que su trabajo le permite, está pendiente de él. Es diabético e hipertenso. Hace unos meses que no sale a la calle, pues vive en un segundo sin ascensor y comenzó a notar que le dolían las piernas al andar, siendo diagnosticado de enfermedad arterial periférica. Presentaba dos lesiones vasculares en ambas piernas; hasta ahora, iba al centro de salud, pero debido a sus problemas de movilidad ha dejado de acudir. Su enfermera acude a domicilio, pero no con la frecuencia debida, Pedro dice que "esa chiquilla siempre va corriendo". Actualmente Pedro presenta signos claros de infección, y ha sido derivado al servicio de urgencias por presentar dolor, hiperglucemia y fiebre.

El caso de Pedro hace unos años era la excepción a la regla y, ahora, se está convirtiendo en la norma. Quizá la enfermera de Pedro no realiza las curas ni con el tiempo ni con la frecuencia deseada debido a la organización del sistema sanitario, donde la carga burocrática y asistencial impide que esto sea así; el soporte familiar es escaso y, la pluripatología, una realidad. En este caso, como pasa en muchos otros, una vez que el paciente ingrese en el hospital, donde se realizarán curas regladas, su cuidador se negará al alta hospitalaria a no ser que se le asegure un seguimiento en primaria o, incluso, hasta el cierre de las lesiones, algo ciertamente imposible.

Desde la visión de Cuidados Paliativos abogamos por unas medidas terapéuticas adaptadas a la situación clínica del paciente: ¿qué es realmente lo que ayuda al paciente?, ¿qué es bueno para el paciente?, la importancia de los detalles...

La muerte en nuestra sociedad se esconde, como lo hacen las úlceras bajo las sábanas (1) o las heridas vasculares tras los pantalones. En el siglo XXI, era de la tecnología, los profesionales sanitarios estamos entrenados para luchar contra la enfermedad y nos resulta incómodo el moribundo. Nos preparamos o informamos en la vida para muchos momentos que puede que nunca lleguen, pero no para la muerte; la gente muere en el hospital, a los niños se les aparta de la enfermedad y de la muerte, evitando que elaboren estrategias futuras para enfrentarse a estas situaciones en su vida adulta.

Cuando llega la tan temida frase "no hay nada que hacer", el miedo al abandono y al sufrimiento se apodera del paciente y familia. Siempre hay que ofrecer cuidados orientados a mejorar, conservar o promover la calidad de vida de los pacientes con enfermedades en fase terminal (oncológicos o no oncológicos). Enfermería es un pilar fundamental en los Cuidados Paliativos, no en vano se maximizan los cuidados y se minimizan las terapias activas. Debemos garantizar que los pacientes terminales, oncológicos o no, tengan un adecuado control sintomático, tanto físico como psicológico.

Cuando nos derivan algún paciente vascular a Cuidados Paliativos, suele ser en el contexto de un proceso agudo en el que se ha descartado revascularización y/o amputación. En estos casos tenemos que priorizar necesidades y formular objetivos razonables y realistas, desde una posición activa y de evaluación constante, a pesar de que persista la idea de no poder "curar".

Se invierte mucho trabajo en cambiar hábitos de vida y en prevención de lesiones vasculares, pero no cabe duda de que muchas de ellas son resultado del aumento de la esperanza de vida, sumado a la asociación de una o varias enfermedades crónicas y a los efectos de la polimedicación.

Las heridas deben enmarcarse dentro de un todo que es el paciente. En función de ese todo se marcarán los objetivos terapéuticos, sin obviar nunca las expectativas y preferencias de los pacientes. ¿Si realmente se les explicara a muchos pacientes el objetivo de sus citas médicas acudirían a ellas?

Dentro de esta cronicidad presente en los pacientes con lesiones vasculares se precisa de una respuesta anticipada, multidisciplinar y continuada, no tanto enfocada a una curación imposible, como a evitar descompensaciones o recaídas.

Es evidente que se hace necesario un trabajo de colaboración interniveles, trasladando a los domicilios los cuidados que necesitan estos pacientes y evitando traslados innecesarios a los centros hospitalarios. Debería haber profesionales de referencia, a nivel hospitalario, a los que poder consultar, así como poder disponer de la tecnología para consultoría como puede ser la Telemedicina.

No pretendo con todo esto negar los mejores tratamientos que marcan las Guías de Práctica Clínica ni limitar los recursos que necesitan los pacientes con lesiones vasculares, pero sí hacer una reflexión sobre lo que realmente es una asistencia individualizada y que ayuda al paciente, aunque al profesional le suponga tener que justificar sus decisiones; ahí radica el verdadero principio de Justicia.

En la actualidad asistimos a un movimiento de Humanización de la asistencia sanitaria que habría que preguntarse cuándo la perdimos. Parece incoherente que una actividad hecha por personas y para personas esté deshumanizada. 
En este punto la enfermería debería asumir el liderazgo, y os recomiendo hacer uso de la herramienta más poderosa que conozco, la palabra.

\section{Bibliografía}

1. Hibbs P. The Economics of Pressure Sore Prevention. En: Bader DL (editor). Pressure Sores - Clinical Practice and Scientific Approach [Internet]. Palgrave, London; 1990. p.35-42 [cited 2019 May 7]. Available from:

http://link.springer.com/10.1007/978-1-349-10128-3_4

María Moreno Benítez Supervisora de Cuidados de la Unidad Gestión Clínica de Cuidados Paliativos Hospital Universitario Reina Sofía de Córdoba. 